\title{
Cost Effectiveness of Peginterferon Alfa-2b Combined with Ribavirin for the Treatment of Chronic Hepatitis $C$ in Brazil
}

\author{
Marcelo Cunio Machado Fonseca ${ }^{1}$, Gabriela Tannus Branco de Araújo ${ }^{1}$ and Denizar Vianna Araújo ${ }^{2}$ \\ ${ }^{1}$ Federal University of São Paulo; São Paulo, SP, Brazil; ${ }^{2}$ State University of Rio de Janeiro; Rio de Janeiro, RJ, Brazil
}

\begin{abstract}
The treatment of chronic hepatitis C (CHC) with peginterferon alpha-2b/ribavirin (PegIFN + Rib) produced larger sustained viral response (SVR) compared to the conventional (non-pegylated) interferon/ribavirin (IFN + Rib), but its cost-effectiveness was not assessed in Brazil. We developed a Markov model to mirror the natural disease history and cohorts of patients with hepatitis C virus (HCV), that received PegIFN + Rib or IFN + Rib treatment for 48 or 24 weeks, according to viral genotype and liver histology. The SVRs for the treatments PegIFN + Rib and IFN + Rib were respectively $48 \%$ and $34 \%$ (genotype 1 ), and $88 \%$ and $80 \%$ (genotype non-1). Three Delphi panels were conducted with hepatologists and intensivists, and another one with oncologists. The costs are expressed in 2006 Brazilian Reais (R\$) and the benefits were discounted at 3\%. In genotype 1 HCV patients, PegIFN + Rib increases the life expectancy (LE) in 0.51 year, and the quality-adjusted life years (QALY) in 0.78, as compared to IFN + Rib. In genotype non-1 HCV patients, PegIFN + Rib increases the LE in 0.29 years and the QALY in 0.44 years, as compared to IFN + Rib. The incremental cost-effectiveness rate, considering all the genotypes, was of $\mathbf{R} \$ 19,848.34$ per QALY. Peginterferon alpha-2b with ribavirin is a cost-effective therapy for the treatment of naïve CHC adult patients compared to the interferon alpha-2b and ribavirin regime, irrespective of the viral genotype. Key-Words: Hepatitis C, cost-benefit analysis, effectiveness, interferons.
\end{abstract}

Hepatitis $\mathrm{C}$ is an infection generally presenting a slow progression [1], and its occurrence and prevalence within the population was not yet completely elucidated [2].

In a study developed in the city of São Paulo, an estimate prevalence of $1.42 \%$ (CI $0.70 \%-2.42 \%$ ) for hepatitis C was found, which, when projected to the entire Brazilian territory, results in a figure between 1.1 and 3.4 million of HCV infected people [2].

Hepatitis C virus (HCV) genotyping is important to define the treatment time: 48 weeks for genotype 1 and 24 weeks for other genotypes. The treatment aim is to achieve a sustained viral response (SVR), which is defined as the absence of detection of serum HCV RNA at the treatment final, and six months later as well; to confirm this condition, an essay with sensitivity of, at least, 100 copies (50 IU) per milliliter was used.

Interferon alpha/ribavirin (IFN + Rib) association has become the treatment gold-standard for C hepatitis from 1998 on [3].

In order to improve the efficacy, side effects profile and the therapeutic scheme itself, pegylated-interferons alpha (PegIFN) have been developed, and are currently considered as the treatment gold-standard for hepatitis C [4].

There are two different products available in the Brazilian market, the peginterferon alpha $2 \mathrm{~b}$ weighing $12 \mathrm{kD}$, and the peginterferon alpha 2a weighing $40 \mathrm{KD}$.

In two multicentric, double-blind, randomized clinical trials using ribavirin in both treatment arms ("IFN" arm and

Received on 18 March 2009; revised 12 June 2009.

Address for correspondence: Dr. Marcelo Cunio Machado Fonseca. Avenida Higienópolis, 240 - apto 52C. Higienópolis - São Paulo - São Paulo - Brazil. Zip code: 01238-000.

The Brazilian Journal of Infectious Diseases 2009;13(3):191-199. (C) 2009 by The Brazilian Journal of Infectious Diseases and Contexto Publishing. All rights reserved.
"PegIFN" arm), the global SVR rate achieved by peginterferon alpha 2a was 56\% [5], and by peginterferon alpha 2b 54\% [6].

The health system is concerned about hepatitis $\mathrm{C}$, because the great period of infection for this disease occurred in the 80's [7], and, taking in account the disease progression [6] and that the therapeutic results are not yet satisfactory, it is expected that the great impact, in terms of number of people carrying the disease as well as the costs involved, will occur in the first two decades of this third millennium.

Due to the clinical course of the infection, it is improper or even feasible to conduct controlled and randomized clinical trials, to investigate the medical-economic impact that better SVR rates could represent [8].

It is unknown whether the short-term costs will be compensated by the possible savings (lesser complications and transplantations) or, even, the extension in which better response rates from pegylated interferons will represent, in terms of life years or quality of life.

As treatment decisions have to be taken right now, we built an analytic decision model to assess both the long-term 'clinical' and 'cost-effectiveness' results that are currently obtained from the treatment of chronic hepatitis C in Brazil, using for this purpose the best available information, although still imperfect [8].

\section{Material and Methods}

We built the model using decision analysis techniques [9]. The analysis was developed in a hypothetical cohort of 30 year-old men and women with chronic hepatitis C, settled in the 2006 Brazilian health system. The primary study perspective is that of private medicine (insurances, HMOs, cooperatives, self-managements).

The adopted data sources were the medical literature [6]; published official prices for medications, procedures, and hospital supplies; and Brazilian population statistics. 
The determination of actual costs of hepatitis $C$ treatment was performed through a microcosting process based on modified Delphi panels [10].

Values should be divided by 2.18 to convert the economic result to 2006 US dollars.

Markov Model for Chronic Hepatitis C

A Markov model has been developed for the natural history of chronic hepatitis $\mathrm{C}$.

The health status were based on histology, presence or absence of viremia; presence of uncompensated hepatic disease; hepatocellular carcinoma or hepatic transplantation; describing the following conditions: remission, mild hepatitis $\mathrm{C}$, moderate hepatitis $\mathrm{C}$, hepatocarcinoma, cirrhosis or uncompensated cirrhosis, to be submitted to hepatic transplantation, to be transplanted, and death. Due to the large variability in treatment and costs, uncompensated cirrhosis health status, was further split in ascytis, refractory ascytis, hemorrhagic varices and hepatic encephalopathy. The prevalence of genotype 1 in Brazil is 74\% [2].

The simulation starts after the diagnose of chronic hepatitis $\mathrm{C}$, and assumes three groups of patients: one treated with conventional IFN, another with PegIFN alpha 2b of 12 $\mathrm{kD}$, and a non-treated group of patients. Every year, the patients transit between the health status categories. The model considers that healed patient will not have hepatitis $\mathrm{C}$ recurrence. The analysis compares the evolution of a disease treated with PegIFN alpha 2b of $12 \mathrm{kD}$ given subcutaneously, with a once per week dose of $1.5 \mathrm{mg} / \mathrm{kg}$, associated with oral ribavirin 1000-1200 mg/day (PegIFN + Rib) or, IFN alpha 2b, conventional, non-pegylated, given subcutaneously, with dose of $3 \mathrm{MU}$ three times per week (IFN + Rib), also associated with oral ribavirin 1,000-1,200 mg/day.

\section{Time Window}

Due to the slow progression of chronic hepatitis $C$ [8], the base case was analyzed for a life-time period.

\section{Clinical Outcomes}

The clinical efficacy outcomes used were global SVR, SVR for genotype 1, and SVR for genotype non-1 [6]. The model made the extrapolation of these efficacy data for effectiveness outcomes: number of life years gained and number of qualityadjusted life years gained.

\section{Delphi Panel}

The modified Delphi panels are used in order to obtain data and develop consensus in pharmacoeconomic studies [10]. Two rounds of Delphi panels were developed, always with the same experts, to allow the consensus.

Following categories of professionals were excluded from the panel: physicians that are somehow linked to the pharmaceutical industry, such as speakers, consultants, or employees; or those occupying positions in universities: professors, lecturers, and physicians occupying positions within medical associations: directors, presidents. These professionals were excluded because, as opinion leaders, during the Delphi panel process they could possibly influence the opinion of other professionals.

The modified Delphi panel was developed with six hepatologists; and for the status of hepatocarcinoma and hepatic encephalopathy, with six oncologists and six intensivists, respectively.

The local management for the status of mild and moderate chronic hepatitis $\mathrm{C}$, cirrhosis, ascytis, refractory ascytis, esophageal varices, hepatic encephalopathy, and hepatic transplantation were equal for all the studied schemes.

\section{Microcosting and Costs Determination}

Microcosting is the process to identify and measure every resource used, assigning values and integrating such information thereafter. After this process, all values were determined for the administration of each therapeutic scheme as well as their consequences, and costs related to the evolution of the treated hepatitis $\mathrm{C}$ with each treatment studied.

\section{Discount Rate}

The process of "discounting” assumes that the expended or saved money, and the saved or lost years in the future, do not have the same value as today. This process decreases the future costs and life years (consequences), every year, according to a fixed percentage rate [11].

We used a discount rate of 3\% [12]. Sensitivity analyses were developed with discount rates between $0 \%$ and $5 \%$.

\section{Cost-Effectiveness Analysis}

The cost-effectiveness analysis compares the costs and clinical outcomes linked to effectiveness for different therapeutic alternatives.

The incremental cost-effectiveness rate (ICER) represents the additional cost and effectiveness obtained, when the PegIFN + Rib regime is compared to the IFN + Rib regime.

\section{Quality of Life}

There are two studies in which the utilities, for every health states related to chronic hepatitis C, are determined by a panel of hepatologists familiarized with the disease, and the disease treatment with interferon [13,14]. In our study, the utility values for each health states are the same for the PegIFN + Rib arm and IFN + Rib arm. Table 1 presents the costs and utilities per every health status used in the model.

\section{Cost-Utility Threshold}

There is not an ICU (Incremental Cost-Utility) threshold in Brazil being considered as ideal for the acceptance of a given health intervention. Therefore, we used the value established by the World Health Organization (WHO), corresponding to three times the per capita gross domestic 
Table 1. Costs and utilities per health status, per patient.

\begin{tabular}{lrr}
\hline Health status & Cost (R\$) [15] & Utilities [16] \\
\hline Remission & 789.10 & 1,00 \\
Mild chronic hepatitis C & $1,069.30$ & 0,98 \\
Moderate chronic hepatitis C & $1,276.80$ & 0,92 \\
Compensated Cirrhosis & $1,522.42$ & 0,82 \\
Ascytis & $15,931.79$ & 0,75 \\
Refractory ascytis & $31,352.05$ & 0,52 \\
Hemorrhagic varices & $21,427.21$ & 0,55 \\
Hepatic encephalopathy & $106,922.08$ & 0,53 \\
Hepatocarcinoma & $20,884.35$ & 0,55 \\
Hepatic transplantation & $136,900.00$ & $0,5[17]$ \\
Subsequent hepatic transplantation & $10,540.00$ & $0,7[17]$ \\
\hline
\end{tabular}

Values should be divided by 2.18 in order to convert the economic results to 2006 US dollars.

product (GDP), as a threshold for cost-effectiveness/utility $[18,19]$.

According to the Brazilian Institute of Geography and Statistics (Instituto Brasileiro de Geografia e Estatística IBGE), the 2006 per capita GDP value is R $\$ 12,491.00$ [20]. Therefore, if a health procedure presents an ICER lower than $\mathrm{R} \$ 37,493.00$ in Brazil, it may be considered as being costeffective.

Sensitivity Analysis and Validation

The role of the sensitivity analysis is to test the stability of the results when varying different model parameters. These model parameters are changed, varying their values within a plausible range found in the literature and checking the related effect on the global model outcome. If the global outcome of the strategy under analysis remains stable with the variation of a given parameter value, then the model outcome is insensitive to the variation of this parameter being assessed. The model was recalculated with univariate and bivariate adjustments.

The sensitivity analysis was performed for the following parameters inserted in the model:

- Clinical events: transition probability from mild chronic hepatitis $\mathrm{C}$ to remission; from mild chronic hepatitis $\mathrm{C}$ to moderate chronic hepatitis $\mathrm{C}$; from moderate chronic hepatitis C to cirrhosis; from moderate chronic hepatitis C to hepatocarcinoma; from cirrhosis to ascytis; from cirrhosis to hemorrhagic varices; from cirrhosis to hepatic encephalopathy; from cirrhosis to hepatocarcinoma; from ascytis to refractory ascytis; from ascytis to death; from refractory ascytis to death; from hemorrhagic varices to death in the first year; from hemorrhagic varices to death in the subsequent years; from hepatic encephalopathy to death in the first year; from hepatic encephalopathy to death in the subsequent years; from hepatocarcinoma to death; from uncompensated cirrhosis to hepatic transplantation; from hepatic transplantation to death in the first year; from hepatic transplantation to death in the subsequent years.
- Economic parameters: cost of mild chronic hepatitis C; moderate chronic hepatitis C; cirrhosis; ascytis; refractory ascytis; hemorrhagic varices; hepatic encephalopathy; hepatocarcinoma; hepatic transplantation; subsequent years to transplantation; mild hepatitis C utility; moderate hepatitis C utility; cirrhosis utility; ascytis utility; refractory ascytis utility; hemorrhagic varices utility; hepatic encephalopathy utility; hepatocarcinoma utility; hepatic transplantation utility; hepatic transplantation utility subsequent years; healed utility; discount rate; price of the drugs used in the treatment.

As uncertainty could occur with any of the model parameters, we performed a Monte Carlo simulation with ten thousand interactions that simultaneously varies all of the above mentioned parameters. In order to check the internal validity of our model, we developed many tests and debugging processes. The external validation was performed comparing the results projected by the model with external epidemiologic data not used in this model [21].

\section{Data Sources}

The standard treatment and the health care resource utilization values came from the Delphi panel. The values used for prices assignment are based on public sources.

Initial Parameters and Probabilities

Initial Parameters

The cohorts that passed through the model simulation had a $74 \%$ prevalence for genotype 1 , and $26 \%$ for non-1 genotypes [2].

In the simulation, two cohorts received effective treatment; one of them with conventional IFN alpha 2b, and the other with PegIFN alpha $2 \mathrm{~b}$ of $12 \mathrm{kD}$; the third cohort simulated the natural disease evolution, without any treatment.

The average body weight of Brazilian patients receiving treatment for chronic hepatitis C is $76.7 \mathrm{~kg}$ and $64.9 \mathrm{~kg}$ for male and female patients, respectively [22]; therefore, the ribavirin dose given to these patients is higher than $10.6 \mathrm{mg} /$ 
kg. Furthermore, we used the response rates being compatible with the higher dose of ribavirin per kilogram [6].

The treatment time was 48 weeks for genotype 1 , and 24 weeks for the other genotypes, for both treatment arms.

Genotype 1 patients were submitted to quantification of viral titer by means of a PCR test: after 12 weeks in the cohort with PegIFN alpha 2b, and 24 weeks in the cohort with conventional IFN [23].

Patients not presenting a significant decrease in their individual viral load had their treatments interrupted [5, 22].

\section{Probabilities}

The probabilities inherent to the natural history of patients with mild chronic hepatitis $\mathrm{C}$ (transition to moderate hepatitis) and moderate CHC (progression to cirrhosis or hepatocarcinoma) were obtained from three retrospective observational studies [24-26]. In patients with mild chronic hepatitis $\mathrm{C}$, the yearly probability of spontaneous disease resolution comes from two studies $[27,28]$.

The progression of patients with compensated cirrhosis (development of hepatocarcinoma and uncompensated cirrhosis) was based on a study from Fattovich et al. [29]. As the literature suggests that mortality due to uncompensated cirrhosis is different, depending on its presentation, we stratified the uncompensated cirrhosis into different categories: ascytis, hemorrhagic varices, hepatic encephalopathy, and ascytis refractory to treatment [8].

In patients with ascytis, after three years of follow-up, Salerno has detected a yearly mortality of $11 \%$ and an evolution probability to refractory ascytis of $6.7 \%$; for patients with refractory ascytis, the yearly probability of death increased to $33 \%$ [30].

Patients with hemorrhagic esophageal varices had a mortality rate of $40 \%$, in the first year, and of $13 \%$ in the three subsequent years of follow-up [31].

For patients presenting hepatic encephalopathy, but without hemorrhagic varices, the mortality rate was $68 \%$ in the first year, and $40 \%$ in the following years [32].

In relation to hepatocarcinoma, the mortality rate is $86 \%$ [33].

A total of 792 hepatic transplantations were conducted in Brazil during 2003 [34]. The overall hepatic transplantation rate was of 4.95 per million, i.e., 33\% of the United States rate, where the yearly transplantation rate in patients with hepatitis $C$ is $3.1 \%$. In such a way, we estimate the transplantation probability for hepatitis C patients in Brazil as 1.023\% (33\% of 3.1\%).

The mortality rates for the first post-transplantation year, and for the subsequent years, come from three studies [35-37].

Table 2 shows the annual probabilities of disease progression used in this model.

The model assumes for both therapeutic schemes that, in case of therapeutic failure, the probabilities of disease progression are the same as the natural disease evolution. Therefore, the difference between the treatment study arms are the response rates achieved by the different studied therapeutic regimes.
Other Causes for Mortality

The yearly risk of death was obtained from the Brazilian vital statistics [38].

\section{Results}

Effectiveness - Life Years Gained

The model projects a life expectation of 18.71 years for the non-treated patients' cohort. When adjusted for quality of life, it is 16.80 years.

There is a gain of 2.23 years (12\%) for patients treated with PegIFN alpha 2b, and of 1.72 (9\%) year for those treated with IFN alpha $2 b$.

In relation to the IFN alpha $2 \mathrm{~b}$ regime, the PegIFN regime resulted in an increase of $2.5 \%$ in the global life expectancy, a life time window.

In patients with genotype 1 , PegIFN alpha $2 \mathrm{~b}$ resulted in an increase of $2.5 \%$ in life expectancy. And the life expectancy increase was of $1.3 \%$ for non-1 genotype patients, with IFN alpha 2 b regime.

\section{Effectiveness - Quality of Life}

When the life years gained are adjusted for the quality of life, the model projects better results for the treated populations versus the natural disease evolution.

There are gains of 3.39 years for patients treated with PegIFN alpha 2b (20\%), and 2.61 years for patients treated with IFN alpha $2 \mathrm{~b}$ (15.5\%).

The PegIFN alpha $2 \mathrm{~b}$ regimen resulted in an increase of $4 \%$ in quality adjusted life years gained, corresponding to 0.78 quality adjusted life years gained in relation to the IFN alpha $2 \mathrm{~b}$ regimen.

In the non-1 genotype patients, the treatment with PegIFN alpha $2 \mathrm{~b}$ resulted in an increase of $2 \%$ in the patients' quality adjusted life expectancy, meaning 0.44 quality adjusted life years in an entire life window, in relation to the IFN alpha $2 b$ regime.

\section{Economical Results}

The average cost of a patient with chronic hepatitis $\mathrm{C}$ along an entire life is $\mathrm{R} \$ 39,147.32$.

Considering the life time window, the average cost discounted by $3 \%$, for the patient who received PegIFN alpha 2b was of $\mathrm{R} \$ 59,782.93$; and for the patient who received IFN alpha $2 \mathrm{~b}$ was of $\mathrm{R} \$ 44,334.25$.

The costs for the health states of mild chronic hepatitis $\mathrm{C}$ and moderate chronic hepatitis $\mathrm{C}$ are equal for the three studied cohorts (patients without treatment, being treated with PegIFN alpha 2b or, otherwise, conventional IFN alpha 2b), because none of these patients received treatment yet, and all of them will be treated at the same time, in all cohorts.

The costs related to all health states are constantly higher for non-treated patients, except for mild chronic hepatitis $\mathrm{C}$ and moderate chronic hepatitis $\mathrm{C}$.

The patients treated with PegIFN alpha 2b present lower cost in all health states following moderate chronic hepatitis 
Table 2. Yearly probabilities of disease progression in patients with chronic hepatitis C [13].

\begin{tabular}{lcc}
\hline Initial status & Event (Reference) & Yearly probability (\%) \\
\hline Mild chronic hepatitis & Remission & 0.2 \\
Moderate chronic hepatitis C & Moderate chronic hepatitis C & 4.1 \\
& Cirrhosis & 7.3 \\
Cirrhosis & Hepatocarcinoma & 2.1 \\
& Ascytis & 1.5 \\
& Hemorrhagic varices & 0.4 \\
Ascytis & Hepatic encephalopathy & 1.5 \\
& Hepatocarcinoma & 6.7 \\
Refractory ascytis & Refractory ascytis & 11.0 \\
Hemorrhagic varices & Death & 33.0 \\
& Death & 40.0 \\
Hepatic encephalopathy & Death 1st year & 13.0 \\
Hepatocarcinoma & Death subsequent years & 68.0 \\
Uncompensated Cirrhosis & Death $1^{\text {st }}$ year & 40.0 \\
Hepatic transplantation & Death subsequent years & 86.0 \\
& Death & 1.023 \\
\hline
\end{tabular}

$\mathrm{C}$, irrespective to the viral genotype. The area under the expenses curve in relation to time of the health states of cirrhosis, uncompensated cirrhosis, hepatic transplantation, and hepatic transplantation-subsequent years for IFN alpha $2 \mathrm{~b}$ is higher than for PegIFN alpha 2b, not only due to the higher costs achieved, but also because these costs remain in such high levels longer than for PegIFN alpha $2 b$.

\section{Cost-Utility}

In an entire life time window, within the global population, there is a gain of 0.78 quality adjusted with PegIFN alpha $2 b$ compared to IFN alpha $2 \mathrm{~b}$, however, there is also an incremental cost of $\mathrm{R} \$ 15,448.68$. Therefore, the point estimate cost-utility of PegIFN alpha $2 \mathrm{~b}$ in relation to IFN alpha $2 \mathrm{~b}$ is $\mathrm{R} \$ 19,848.34$. The cost utility rates of PegIFN alpha 2b and IFN alpha $2 \mathrm{~b}$ in relation to no treatment are $\mathrm{R} \$ 6,087.20$ and $\mathrm{R} \$ 1,987.33$, respectively.

\section{Sensitivity Analysis - Marginal Cost-Utility}

In the univariate analysis, the incremental cost-utility varied between $\mathrm{R} \$ 14,322.93$ and $\mathrm{R} \$ 32,436.38$ for each quality adjusted life year gained, after the variation of transition probabilities and costs within the range of plausible values, and increasing or decreasing by $50 \%$ the costs of the different health states.

The model was insensitive to all univariate variations of transition probabilities and costs.

In a bivariate analysis, using the clinical and economical parameters with the widest variation, transition probability of mild chronic hepatitis $C$ to remission and discount rate, respectively for the whole population, the incremental costutility is sensitive to a discount level of $5 \%$, unless the spontaneous remission is probability higher than 0.001 yearly.
This same analysis splitting the population in patients with genotype 1 and non- 1 has demonstrated that for genotype 1 patients, the incremental cost-utility is sensitive to a discount level of $5 \%$, unless the spontaneous remission probability is higher than 0.004 yearly. For patients with non-1 genotype virus, the incremental cost-utility was never above $\mathrm{R} \$ 37,493.00$, even when the discount rate was 5\%, and the spontaneous remission probability lower than 0.000 yearly.

Monte Carlo Probabilistic Sensitivity Analysis

Within an entire life time window, the mean cost-utility obtained through the Monte Carlo simulation with ten thousand interactions for the whole cohort, for patients with chronic hepatitis $C$ due to genotype 1 virus, and due to genotype non-1 virus was of $\mathrm{R} \$ 17,774.10, \mathrm{R} \$ 16,523.62$, and $\mathrm{R} \$ 12,583.45$, respectively.

The outcomes of the Monte Carlo simulation are shown in Figures 1 and 2, in which the cost-utility rate is presented as a function of a threshold rate. This "threshold -rate" is that which a given healthcare decision maker or payer would be willing to pay, to include a given drug into his/her formulary. For genotype $1 \mathrm{CHC}$ patients, the cost-utility rate found in the model $(\mathrm{R} \$ 23,392.18)$ presents an acceptance probability around $68 \%$, while $90 \%$ of the 10,000 results obtained in the Monte Carlo simulation are below the limit of $\mathrm{R} \$ 37,493.00$ considered, in Brazil, and according to the WHO criteria, as the "threshold -rate" of cost-effectiveness/utility.

For patients with genotype non-1, the cost-utility rate found in the model $(\mathrm{R} \$ 17,083.54)$ presents a probability to be accepted around $65 \%$. We also verified that $95 \%$ of the 10,000 results obtained in the Monte Carlo simulation are below the limit of R\$37,493.00. 


\section{Model Validation}

The external model validation was performed comparing the cirrhosis development probability, after 20 years of evolution of chronic hepatitis $\mathrm{C}$, projected by the model, with the same parameter extracted from studies examining the longterm prognosis of chronic hepatitis $C$. The probability of developing cirrhosis, after 20 years of natural disease evolution estimated by our model, was of $17.3 \%$, which is consistent with the same probability published in other studies [21,39 - 43].

\section{Discussion}

This study examined the effectiveness and costeffectiveness (utility) of treating chronic hepatitis $\mathrm{C}$ with PegIFN alpha 2b of $12 \mathrm{kD}$, compared to IFN alpha 2b (conventional) regimen in Brazilian patients, 30 years of age in average, using a Markov model to estimate the incremental cost-utility (ICU) in such patients, in the Brazilian 2006 private healthcare setting perspective.

The outcomes projected by this model were compared to the epidemiological data not used to build the model [21]. The epidemiological data usually used for this purpose was the probability to develop cirrhosis after 20 years of chronic hepatitis C natural evolution [21,39,42]. A 17.3\% probability was estimated in a cohort of patients with mild chronic hepatitis $\mathrm{C}$, a value being consistent and coherent with the published studies [21,39-43]. Therefore, the model probably represents with good accuracy the expected course of this disease, in the absence of antiviral treatment [21].

Additionally, the model projected the life expectation and quality adjusted life years for patients receiving no treatment, and achieved results being quite consistent with those from other already published models [21].

The therapeutic regime with PegIFN alpha $2 \mathrm{~b}$ produced an average survival benefit of 0.51 discounted year of life, compared to IFN alpha 2b, in a life-time window. Although a gain of six incremental months of survival could appear tiny, it is consistent with the benefit resulting from other interventions to treat hepatitis C [21].

In genotype 1 patients, the cost-utility rate of PegIFN alpha 2b compared to IFN alpha $2 \mathrm{~b}$ is higher because these patients should be treated for a longer time (48 weeks), have a SVR rate being lower than those for genotype 2 and 3 patients and, hence, they have a higher number of complications resulting from the disease evolution and, consequently, higher expenses and healthcare resources consumption.

The opposite occurs in genotype 2 and 3 patients. They are treated for a shorter period of time, 24 weeks, have higher SVR rate, with lower number of complications due to disease evolution and, therefore, lower consumption of healthcare resources.

However, genotype 1 patients generate larger benefit, in terms of life expectation and quality, in a life-time window, compared to IFN alpha 2b patients.

We could observe as well, that cirrhosis and its complications are the health statuses generating the main differences, in terms of financial resources consumption, between the regimes with PegIFN alpha 2B and conventional IFN alpha 2b.

The expenditure with drugs is $87.6 \%$ larger with the PegIFN alpha $2 \mathrm{~b}$ therapy, but the cost incurred with the disease evolution treatment is $30 \%$ higher with the IFN alpha $2 b$ therapy. Overall, the costs of PegIFN alpha $2 \mathrm{~b}$ are $34.8 \%$ higher than those with IFN alpha 2b. However, with the cost-utility calculations, we could observe that, despite of being more expensive, the PegIFN alpha $2 \mathrm{~b}$ treatment is cost-effective, seen under the WHO point of view related to the Brazilian healthcare market $[15,16]$. This result does not modify when we separately analyze both patients populations, genotype 1 and non-1 patients.

The global calculated cost-utility, R\$19,848.34 per qualityadjusted life year gained is a single point estimation, is subjected to biases due to the uncertainties inherent to the model parameters. These uncertainties were considered by the sensitivity analyses and Monte Carlo simulations.

The incremental cost-utility rates are stable in the vast majority of circumstances, as duly shown by the Monte Carlo simulations.

The Monte Carlo simulation shows that the treatment with PegIFN alpha 2b, along an entire life time window, is costeffective in $90.27 \%$ and $95.54 \%$ of the times, for patients with HCV genotypes 1 and non-1, respectively. This means that, if we consider the value of $\mathrm{R} \$ 37,493.00$, which according to the WHO suggestion is the threshold cost-utility ratio, PegIFN alpha 2 b would have a probability of $90.27 \%$ for patients with genotype $1 \mathrm{HCV}$, and of 95.54\% for patients with genotype non-1 HCV, to be accepted as a cost-effective treatment of chronic hepatitis $\mathrm{C}$.

Except for a single work [21], “utilities” based on patients or on the community are not available, therefore, the patients' preferences have been estimated by experts [8,13,44]. Given the limited data coming directly from patients, we decided to use the already recognized data from literature [8,13].

We should emphasize that the "utilities" used in this model, despite being classic, are lower than those presented in other works [21].

Another topic to be commented is the possibility of our study underestimate the costs related to disease and, probably, underestimate the resource savings resulting from the treatment itself, due to the avoidance of future clinical complications. We used variable costs and have not considered fixed costs, not even those related to loss of productivity. The model also does not include the cost of other treatments for non-responsive patients and, the histological normalization and decrease of hepatocarcinoma incidence in non-responsive patients were not considered, as well.

\section{Limitations of this Model}

The clinical impact of the PegIFN alpha 2b regime was based only in a single clinical trial, by Manns et al., published at Lancet in 2001 [6]. 
Figure 1. Probability of PegIFN alpha 2b being cost effective as a function of a cost utility threshold for patients with genotype 1 chronic hepatitis $\mathrm{C}$

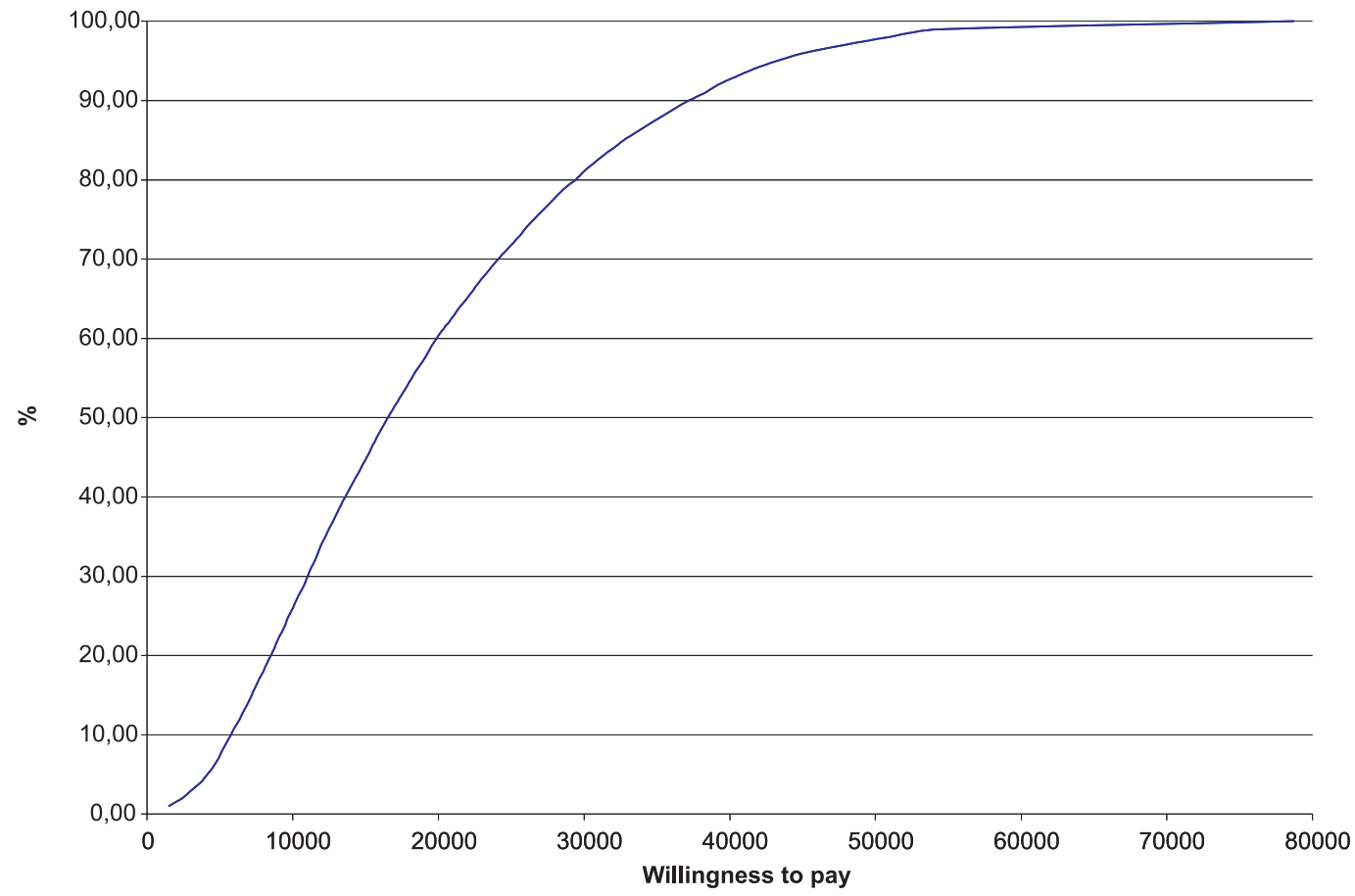

Figure 2. Probability of PegIFN alpha 2b being cost effective as a function of a cost utility threshold for patients with genotype 2 chronic hepatitis $C$

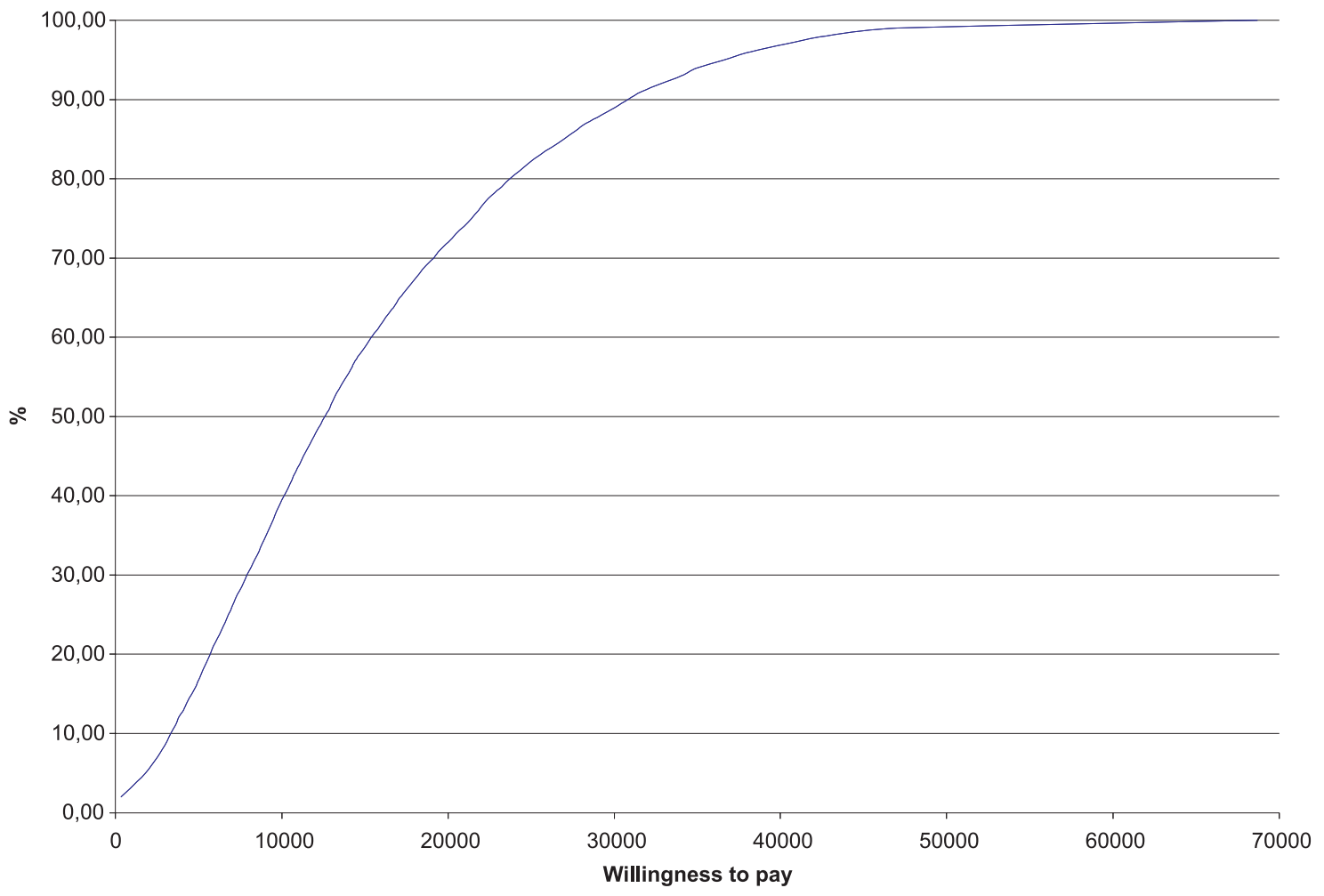

www.bjid.com.br 
Because we do not have "utilities" described for the different chronic hepatitis $\mathrm{C}$ health states for Brazilian patients, the quality adjusted life years may be subject of criticism.

The average clinical management was obtained from Delphi panels with Brazilian hepatologists, oncologists and intensivists; nevertheless, some variability in the cases management is possible, causing some cost differences. Then again, the sensitivity analysis studied this, and the model was not sensitive to these cost parameters.

Although there are many other possible health states that could be inserted in a chronic hepatitis $C$ model, the simplification of the states and their transitions was necessary, in order to obtain a usable Markov model.

But, besides these limitations in the modeling technique, there are advantages that should be pointed out.

The ideal design to demonstrate the possible PegIFN alpha $2 \mathrm{~b}$ regime long-term economic outcomes benefit compared to IFN alpha 2 b regime, would be a naturalistic prospective study, which would require a long follow-up period under the economic perspective (from 15 to 35 years); and this is not feasible.

The use of decision techniques allows the extrapolation of clinical outcomes, beyond the duration of available clinical trials. Validation and sensitivity analyses were performed when feeling that the uncertainty would be big. In this model, the sensitivity analyses have been done with health states costs, utilities, and transition probabilities. These analyses demonstrate the results robustness in relation to the basecase parameters variation.

\section{Conclusion}

The results from this model suggest that the regimen with PegIFN alpha 2b is cost-effective compared to the IFN alpha $2 b$ regimen, in patients with chronic hepatitis C. PegIFN alpha $2 \mathrm{~b}$ is important in the global treatment cost of patients with chronic hepatitis $\mathrm{C}$, however, this apparently voluminous initial investment decreases substantially the subsequent costs due to the chronic disease progression.

\section{References}

1. EASL International Consensus Conference on Hepatitis C. Paris, 26-28, February 1999, Consensus Statement. European Association for the Study of the Liver. J Hepatol 1999;30(5):956-61.

2. Focaccia R., Conceicao O.J., Sette, Jr. H. et al. Estimated Prevalence of Viral Hepatitis in the General Population of the Municipality of Sao Paulo, Measured by a Serologic Survey of a Stratified, Randomized and Residence-Based Population. Braz J Infect Dis 1998;2(6):269-84.

3. McHutchison J.G., Gordon S.C., Schiff E.R. et al. Interferon alfa$2 \mathrm{~b}$ alone or in combination with ribavirin as initial treatment for chronic hepatitis C. Hepatitis Interventional Therapy Group. N Engl J Med 1998;339(21):1485-92.

4. World Health Organization. Hepatitis C [text on the Internet]. Geneva: WHO; 2002 [cited on 2006 Mar 21]. Available at: http://www.who.int/csr/disease/hepatitis/whocdscsrlyo 2003/en/ index.html
5. Fried M.W., Shiffman M.L., Reddy K.R. et al. Peginterferon alfa2a plus ribavirin for chronic hepatitis $\mathrm{C}$ virus infection. $\mathrm{N}$ Engl J Med 2002;347(13):975-82.

6. Manns M.P., McHutchison J.G., Gordon S.C. et al. Peginterferon alfa-2b plus ribavirin compared with interferon alfa-2b plus ribavirin for initial treatment of chronic hepatitis C: a randomised trial. Lancet 2001;358(9286):958-65.

7. Terrault N. Chronic viral hepatitis in the United States: update on viral hepatitis. In: American Association for the Study of Liver Diseases Annual Meeting; 2000; Dallas. Postgraduate Course. Dallas: American Association for the Study of Liver Diseases; 2000. p. 36-46.

8. Bennett W.G., Inoue Y., Beck J.R. et al. Estimates of the costeffectiveness of a single course of interferon-alpha $2 b$ in patients with histologically mild chronic hepatitis C. Ann Intern Med 1997;127(10):855-65.

9. Recurring events. In Hunink M., Glasziou P., Siegel J. et al. Decision making in health and medicine: integrating evidence and values. Cambridge: Cambridge University Press; 2004. p. 305-38.

10. Evans C. The use of consensus methods and expert panels in pharmacoeconomic studies: practical applications and methodological shortcomings. In: Mallarkey G. Economic Evaluation in Healthcare. Hong Kong: Adis International; 1999. p. $103-11$.

11. Weinstein M.C., Stason W.B. Foundations of cost-effectiveness analysis for health and medical practices. N Engl J Med 1977;296(13):716-21.

12. Lipscomb J., Weinstein M.C., Torrance G.W. Time preference. In Gold M.R., Siegel J.E., Russel L.B., Weinstein M.C. (edits). Costeffectiveness in health and medicine. New York: Oxford University Press; 1996. p. 214-46.

13. Wong J.B., McQuillan G.M., McHutchison J.G., Poynard T. Estimating future hepatitis C morbidity, mortality, and costs in the United States. Am J Public Health 2000;90(10):1562-9.

14. Wong J.B., Poynard T., Ling M.H., Albrecht J.K., Pauker.G. Costeffectiveness of 24 or 48 weeks of interferon alpha-2b alone or with ribavirin as initial treatment of chronic hepatitis C. International Hepatitis Interventional Therapy Group. Am J Gastroenterol 2000; 95(6):1524-30.

15. Fonseca M.C.M., Araujo G.T.B. Medical resource use and direct medical cost of chronic hepatitis C virus infection (HCVI) in Brazil. Value Health 2005;8(6):122A.

16. Wong J.B., Bennett W.G., Koff R.S., Pauker S.G. Pretreatment evaluation of chronic hepatitis C: risks, benefits, and costs. JAMA 1998;280(24):2088-93.

17. El Saadany S., Coyle D., Giulivi A., Afzal M. Economic burden of hepatitis $\mathrm{C}$ in Canada and the potential impact of prevention Results from a disease model. Eur J Health Econ 2005;6(2):15965.

18. Baltussen R., Sylla M., Mariotti.SP. Cost-effectiveness analysis of cataract surgery: a global and regional analysis. Bull World Health Organ 2004;82(5):338-45.

19. World Health Organization. Macroeconomics and health: investing in health for economic development. Report of the commission on macroeconomics and health. Geneva: World health Organization; 2001.

20. Instituto Brasileiro de Geografia e Estatística. Brasil em síntese Contas Nacionais [text on the Internet]. Rio de Janeiro: IBGE; 2006 [cited on 2008 Apr 25]. Available at: http://www.ibge.gov.br/ brasil_em_sintese/tabelas/contas_nacionais_tabela01.htm

21. Siebert U., Ravens-Sieberer U., Sroczynski G. et al. Patient-based health-related quality of life in different stages of chronic hepatitis C [abstract]. Hepatology. 2001;34(Suppl1):222A.

22. Focaccia R., Baraldo D.C., Ferraz M.L., Martinelli A.L., Carrilho F.J., Goncales, Jr. F.L. et al. Demographic and anthropometrical analysis and genotype distribution of chronic hepatitis C patients treated in public and private reference centers in Brazil. Braz J Infect Dis 2004;8(5):348-55. 
23. Sullivan S.D., Green J., Patel K.K. et al. The cost-effectiveness of peginterferon alfa-2a (40KD) (Pegasys) plus ribavirin (Copegus) versus interferon alfa-2b plus ribavirin for chronic hepatitis $\mathrm{C}$ (CHC) [abstract]. Value Health 2003;6(3):262A.

24. Takahashi M., Yamada G., Miyamoto R. et al. Natural course of chronic hepatitis C. Am J Gastroenterol 1993;88(2):240-3.

25. Tremolada F., Casarin C., Alberti A. et al. Long-term follow-up of non-A, non-B (type C) post-transfusion hepatitis. J Hepatol 1992;16(3):273-81.

26. Mattsson L., Sonnerborg A., Weiland O. Outcome of acute symptomatic non-A, non-B hepatitis: a 13-year follow-up study of hepatitis C virus markers. Liver. 1993 Oct;13(5):274-8.

27. Yousuf M., Nakano Y., Tanaka E., Sodeyama T., Kiyosawa K. Persistence of viremia in patients with type-C chronic hepatitis during long-term follow-up. Scand J Gastroenterol 1992;27(9):812-6.

28. Yee T.T., Griffioen A., Sabin C.A., Dusheiko G., Lee C.A. The natural history of HCV in a cohort of haemophilic patients infected between 1961 and 1985. Gut 2000;47(6):845-51.

29. Fattovich G., Giustina G., Degos F. et al. Morbidity and mortality in compensated cirrhosis type C: a retrospective follow-up study of 384 patients. Gastroenterology 1997;112(2):463-72.

30. Salerno F., Borroni G., Moser P. et al. Survival and prognostic factors of cirrhotic patients with ascytis: a study of 134 outpatients. Am J Gastroenterol 1993;88(4):514-9.

31. Sclerotherapy for male alcoholic cirrhotic patients who have bled from esophageal varices: results of a randomized, multicenter clinical trial. The Veterans Affairs Cooperative Variceal Sclerotherapy Group. Hepatology 1994;20(3):618-25.

32. Christensen E., Krintel J.J., Hansen S.M., Johansen J.K., Juhl E. Prognosis after the first episode of gastrointestinal bleeding or coma in cirrhosis. Survival and prognostic factors. Scand J Gastroenterol 1989;24(8):999-1006.

33. Okuda K., Ohtsuki T., Obata H. et al. Natural history of hepatocellular carcinoma and prognosis in relation to treatment. Study of 850 patients. Cancer 1985;56(4):918-28.
34. Associação Brasileira de Transplante Órgãos [Internet site] Estatísticas de transplantes. São Paulo: ABTO; 2004 [cited on 2006 Mar 21]. Available at: http://www.abto.org.br/população/ população.asp\#

35. Ascher N.L., Lake J.R., Emond J., Roberts J. Liver transplantation for hepatitis C virusrelated cirrhosis. Hepatology 1994;20(1 Pt 2):24S-27S.

36. Detre K.M., Belle S.H., Lombarddero M. Liver transplantation for chronic viral hepatitis. Viral Hepatitis Rev 1996;2:219-28.

37. Kilpe V.E., Krakauer H., Wren R.E. An analysis of liver transplant experience from 37 transplant centers as reported to Medicare. Transplantation 1993;56(3):554-61.

38. DataSUS [Internet site] Indicadores demográficos. Brasília: DataSUS; 2006 [cite don 2006 Mar 21]. Available at: http:// tabnet.datasus.gov.br/cgi/deftohtm.exe?idb2003/a08.def

39. Alter H.J., Seeff L.B. Recovery, persistence, and sequelae in hepatitis $\mathrm{C}$ virus infection: a perspective on long-term outcome. Semin Liver Dis 2000;20(1):17-35.

40. Niederau C., Lange S., Heintges T. et al. Prognosis of chronic hepatitis C: results of a large, prospective cohort study. Hepatology 1998; 28(6):1687-95.

41. Gordon S.C., Elloway R.S., Long J.C., Dmuchowski C.F. The pathology of hepatitis $\mathrm{C}$ as a function of mode of transmission: blood transfusion vs. intravenous drug use. Hepatology 1993;18(6):1338-43.

42. Seeff L.B., Hollinger F.B., Alter H.J., Wright E.C., Bales Z.B., NHLBI Study Group. Long-term morbidity of transfusionassociated hepatitis (TAH) C [abstract]. Hepatology 1998;28:407A.

43. Liang T.J., Rehermann B., Seeff L.B., Hoofnagle J.H. Pathogenesis, natural history, treatment, and prevention of hepatitis C. Ann Intern Med 2000;132(4):296-305.

44. Shepherd J., Waugh N., Hewitson P. Combination therapy (interferon alfa and ribavirin) in the treatment of chronic hepatitis C: a rapid and systematic review. Health Technol Assess 2000;4(33):1-67. 